\title{
Bell palsy in Lyme disease-endemic regions of Canada: a cautionary case of occult bilateral peripheral facial nerve palsy due to Lyme disease
}

\begin{abstract}
Karen Ho, MD*; Michel Melanson, MD*; Jamsheed A. Desai, MD, BSc*
\section{ABSTRACT}

Lyme disease caused by the spirochete Borrelia burgdorferi is a multisystem disorder characterized by three clinical stages: dermatologic, neurologic, and rheumatologic. The number of known Lyme disease-endemic areas in Canada is increasing as the range of the vector Ixodes scapularis expands into the eastern and central provinces. Southern Ontario, Nova Scotia, southern Manitoba, New Brunswick, and southern Quebec are now considered Lyme diseaseendemic regions in Canada. The use of field surveillance to map risk and endemic regions suggests that these geographic areas are growing, in part due to the effects of climate warming. Peripheral facial nerve palsy is the most common neurologic abnormality in the second stage of Lyme borreliosis, with up to $25 \%$ of Bell palsy (idiopathic peripheral facial nerve palsy) occurring due to Lyme disease. Here we present a case of occult bilateral facial nerve palsy

terrain pour cartographier le risque et les régions endémiques indique que ces zones géographiques s'étendent, ce qui est en partie lié aux effets du réchauffement climatique. La paralysie faciale périphérique est l'anomalie neurologique la plus fréquente au second stade de la borréliose de Lyme, et $25 \%$ des cas de paralysie de Bell (paralysie faciale périphérique idiopathique) sont dus à la maladie de Lyme. Nous présentons ici un cas de paralysie faciale bilatérale occulte liée à la maladie de Lyme et initialement diagnostiqué comme une paralysie de Bell. Dans les régions où la maladie de Lyme est endémique au Canada, les patients présentant une paralysie faciale périphérique unilatérale ou bilatérale doivent être examinés à la recherche de la maladie de Lyme au moyen de tests sérologiques afin d'éviter une erreur de diagnostic. Les tests sérologiques ne doivent pas retarder le début d'un traitement approprié pour une paralysie de Bell présumée.
\end{abstract} due to Lyme disease initially diagnosed as Bell palsy. In Lyme disease-endemic regions of Canada, patients presenting with unilateral or bilateral peripheral facial nerve palsy should be evaluated for Lyme disease with serologic testing to avoid misdiagnosis. Serologic testing should not delay initiation of appropriate treatment for presumed Bell palsy.

\section{RÉSUMÉ}

La maladie de Lyme provoquée par le spirochète Borrelia burgdorferi est une pathologie multisystémique caractérisée par trois stades cliniques: dermatologique, neurologique, et rhumatologique. Le nombre de régions connues où la maladie de Lyme est endémique au Canada augmente au fur et à mesure que le vecteur, la tique Ixodes scapularis, se répand dans les provinces de l'est et du centre. Le sud de I'Ontario, la Nouvelle-Écosse, le sud du Manitoba, le Nouveau-Brunswick, et le sud du Québec sont maintenant considérés comme des régions du Canada où la maladie de Lyme est endémique. Le recours à la surveillance sur le
Keywords: Bell palsy, Canada, endemic regions, facial nerve, Lyme disease

Lyme borreliosis caused by the spirochete Borrelia burgdorferi is a multisystem disorder characterized by three clinical stages: dermatologic, neurologic, and rheumatologic. ${ }^{1}$ Peripheral facial nerve palsy $(\mathrm{PFP})$ is the most common neurologic abnormality in the second stage of Lyme borreliosis. ${ }^{2,3}$ It is estimated that in highly endemic areas, up to $25 \%$ of Bell palsy cases are due to Lyme borreliosis. ${ }^{3}$ Rarely, Lyme PFP may occur prior to the development of a measurable antibody response, ${ }^{3}$ which may lead to the misdiagnosis of (idiopathic) Bell palsy. It is common for Lyme disease to present with bilateral PFP; however, impairment is often asymmetrical, apparent only with

From the *Department of Medicine, Division of Neurology, Queen's University, Kingston, ON.

Correspondence to: Dr. Jamsheed. A. Desai, Queen's University, Department of Medicine, Division of Neurology, Kingston General Hospital, Connell 7-76 Stuart Street, Kingston, ON K7L 2V7; 3jd14@queensu.ca.

This article has been peer reviewed. 
careful examination or with radiographic interrogation, and thus can mimic unilateral PFP. Lyme disease was considered a rare entity in Canada, but with an increasingly warming climate, several regions of Canada are now considered Lyme disease-endemic areas. Primary care and emergency physicians practicing in such regions should be aware of this emerging trend when evaluating cases of facial palsy.

\section{CASE REPORT}

A 62-year-old woman with a past medical history of juvenile rheumatoid arthritis, which has remained quiescent without treatment for 30 years, was sent to the emergency department (ED) by her family doctor after presenting with fatigue, general malaise, and facial weakness. The family physician diagnosed the patient with Bell palsy and started her on prednisone but was puzzled by an elevated erythrocyte sedimentation rate (ESR) of $111 \mathrm{~mm} / \mathrm{h}$ on routine testing. This prompted the family physician to seek a rheumatologic opinion given the patient's past history of juvenile rheumatoid arthritis. After being assessed in the ED, the patient was referred to Neurology due to the facial weakness. The patient volunteered a recent travel history to Switzerland, New York, and Connecticut. She reported a 4-week history of PFP, dysgeusia, and pain in the left occipital and retroauricular regions. She denied hearing loss, hyperacusis, tinnitus, or vertigo. Three weeks earlier, she experienced transient fevers, chills, and a bifrontal headache, followed by a generalized nonpruritic rash consisting of confluent erythematous patches.

On examination, she had a lower motor neuron-type left facial nerve palsy, with impaired taste on the left side of the tongue. Subtle weakness of the right orbicularis oculi was noted. The remainder of her neurologic examination, as well as her general medical examination, was unremarkable. Gadoliniumenhanced brain magnetic resonance imaging revealed bilateral facial nerve enhancement in the distal canalicular and labyrinthine segments, preferentially in the left (Figure 1).

Subsequent electrophysiologic testing showed normal latency and low compound motor action potential amplitudes in both facial nerves. The blink test on electromyography suggested bilateral facial nerve involvement, with the left being affected to a greater degree. Electrocardiography revealed a nonspecific intraventricular conduction delay. The two-tiered serologic testing consisting of enzyme-linked immunosorbent assay followed by Western blot was reactive for Lyme IgG and IgM antibodies. The ESR remained elevated at $111 \mathrm{~mm} / \mathrm{h}$ for 4 weeks despite being treated with high-dose prednisone. Lumbar puncture revealed $13 \times 10^{6}$ nucleated cells, of which $92 \%$ were lymphocytes; the glucose and protein levels and cerebrospinal fluid flow cytometry were normal. Acute and convalescent serology for B. burgdorferi were reactive.

A diagnosis of bilateral facial nerve palsy secondary to Lyme disease was made, and the patient was treated with a 14-day course of doxycycline, with significant improvement in her symptoms and a corresponding decline in ESR values. On discharge home, the patient developed isolated arthralgia in the right knee, which prompted a return to the ED, where the emergency physician made a diagnosis of Lyme arthritis and reinstituted treatment with doxycycline for an additional 4 weeks. At follow-up 3 months posttreatment,

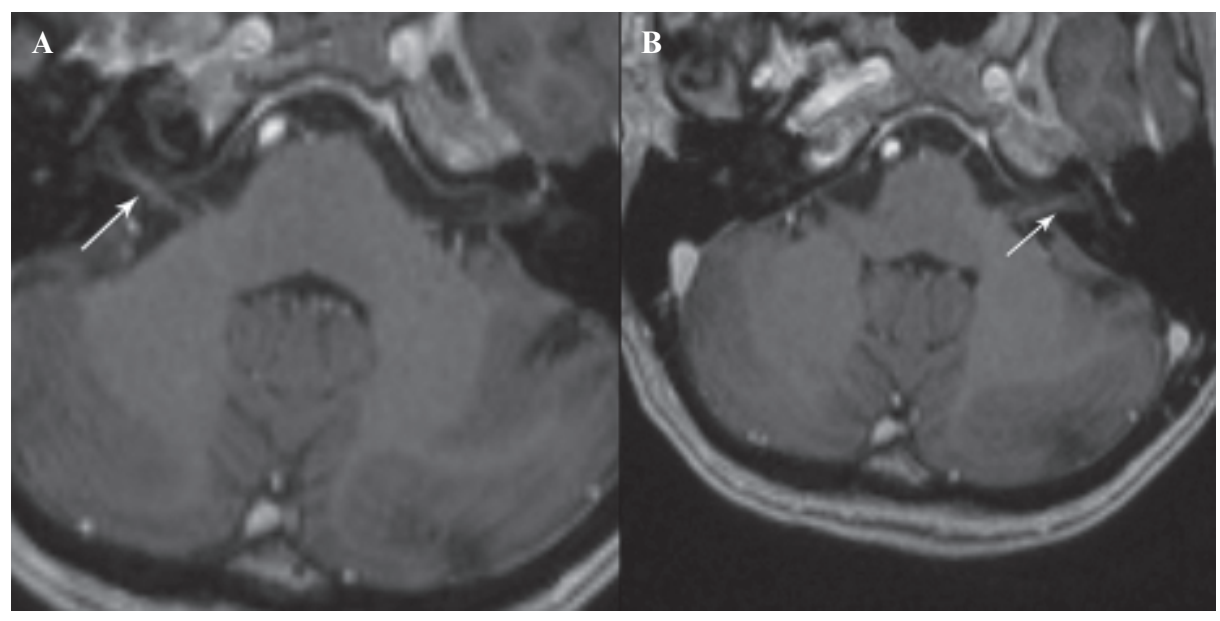

Figure 1. Axial $\mathrm{T}_{1}$-weighted magnetic resonance image with gadolinium. $A$, Faint enhancement in the right facial nerve (arrow). $B$, Enhancement of the left facial nerve (arrow). 
she had achieved almost complete resolution of her facial palsy.

\section{DISCUSSION}

In our case, the clinical presentation of apparent unilateral facial palsy led to an initial misdiagnosis of Bell palsy and treatment with steroids. However, the preceding systemic symptoms and measurement of an elevated ESR prompted a neurologic referral. Radiographic evidence of bilateral facial nerve involvement resulted in an extensive workup and an eventual diagnosis of bilateral Lyme PFP and appropriate treatment with antibiotics.

The number of known Lyme disease-endemic areas in Canada is increasing as the range of the vector Ixodes scapularis expands in the eastern and central provinces. ${ }^{4}$ The use of field surveillance to map risk and endemic regions suggests that these geographic areas are growing, in part due to the effects of climate warming on the spread of tick vectors (Figure 2).5 Human cases of Lyme disease and the use of passive surveillance for ticks have identified concentrations of I. scapularis in southern Ontario, Nova Scotia, southern Manitoba, and New Brunswick. ${ }^{6}$ The possibility of emerging populations of $I$. scapularis in southern Quebec has been confirmed, ${ }^{7}$ and experts caution that the geographic range of I. scapularis-borne zoonoses may expand significantly northward in Canada as a consequence of climate change this century., Although conflicting evidence exists regarding an increased incidence of Lyme disease in Canada, ${ }^{4,9,10}$ increasing incidence in the United States is well established. Of the cases reported in Canada, a proportion of these are related to travel to endemic areas, particularly in the northern United States. Therefore, one might expect a rise in the incidence of Lyme disease in Canada and, therefore, Lyme disease-related PFP. Clinicians should be vigilant when confronted with cases of Bell palsy in Lyme disease-endemic regions.

Although B. burgdorferi infection is known to be associated with bilateral facial nerve palsy, its association with an elevated ESR greater than $100 \mathrm{~mm} / \mathrm{h}$ has been infrequently reported. ${ }^{11,12}$ The patient's symptoms responded well to the initial course of oral doxycycline, and serial measurements of her ESR demonstrated a decline coincident with the onset of treatment. However, the development of arthralgia

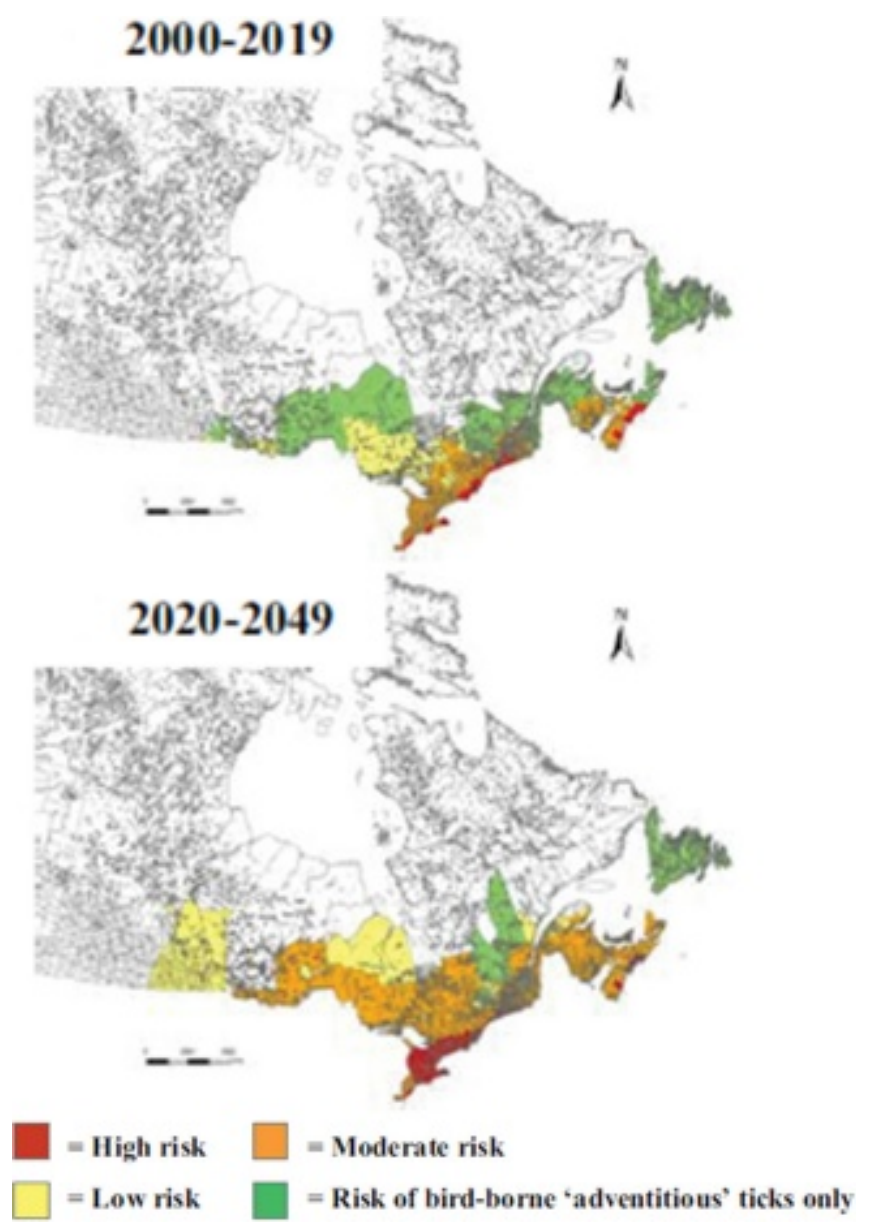

Figure 2. Risk maps for the occurrence of the Lyme disease vector Ixodes scapularis showing high- to low-risk regions of Lyme disease presently and the expected range of expansion with a warming climate. Adapted from Ogden $\mathrm{NH}$ et al. ${ }^{5}$

posttreatment may be attributed to undertreatment of the $B$. burgdorferi infection or the reactivation of underlying rheumatic disease. Exposure to high-dose steroids for several weeks may have led to an immunocompromised state in our patient, promoting active viral infection. At the same time, the threshold for reactivation of her rheumatoid arthritis may be lowered in this context. In our patient, the discovery of bilateral facial nerve palsy, positive acute and convalescent titres for Lyme disease, and the response to doxycycline confirm the diagnosis of Lyme diseaseinduced bilateral PFP.

This case highlights the need for a low threshold to consider Lyme disease in the differential diagnosis of Bell palsy in Lyme disease-endemic regions of Canada. We suggest that patients in these regions (see Figure 2) presenting with PFP should be investigated with Lyme serology as upwards of $25 \%$ of cases of unilateral PFP 
are attributed to Lyme disease in endemic areas. Patients with demonstrable bilateral PFP in endemic areas should definitely be suspected of Lyme disease, and empirical antibiotic treatment regimens should be considered if patients have an accompanying history of preceding systemic or dermatologic findings compatible with Lyme disease. It should be stressed that treatment with steroids should not be delayed in cases of unilateral PFP while serologic testing for Lyme disease is pending.

Competing interests: None declared.

\section{REFERENCES}

1. Steere AC. Lyme disease. N Engl 7 Med 2001;345:115-25, doi:10.1056/NEJM200107123450207.

2. Eppes SC. Diagnosis, treatment, and prevention of Lyme disease in children. Paediatr Drugs 2003;5:363-72.

3. Halperin JJ, Golightly M. Lyme borreliosis in Bell's palsy. Long Island Neuroborreliosis Collaborative Study Group. Neurology 1992;42:1268-70.

4. Ogden NH, Lindsay LR, Morshed M, et al. The emergence of Lyme disease in Canada. CMA7 2009;180:1221-4, doi: $10.1503 /$ cmaj.080148.

5. Ogden NH, St-Onge L, Barker IK, et al. Risk maps for range expansion of the Lyme disease vector, Ixodes scapularis, in Canada now and with climate change. Int 7 Health Geogr 2008;7:24, doi:10.1186/1476-072X-7-24.

6. Ogden NH, Trudel L, Artsob H, et al. Ixodes scapularis ticks collected by passive surveillance in Canada: analysis of geographic distribution and infection with Lyme borreliosis agent Borrelia burgdorferi. $7 \mathrm{Med}$ Entomol 2006;43:600-9, doi:10.1603/0022-2585(2006)43[600:IST $\mathrm{CBP}] 2.0 . \mathrm{CO} ; 2$.

7. Ogden NH, Bouchard C, Kurtenbach K, et al. Active and passive surveillance and phylogenetic analysis of Borrelia burgdorferi elucidate the process of Lyme disease risk emergence in Canada. Environ Health Perspect 2010;118: 909-14, doi:10.1289/ehp.0901766.

8. Ogden NH, Maarouf A, Barker IK, et al. Climate change and the potential for range expansion of the Lyme disease vector Ixodes scapularis in Canada. Int 7 Parasitol 2006;36:63-70, doi:10.1016/j.ijpara.2005.08.016.

9. Ogden NH, Lindsay LR, Morshed M, et al. The rising challenge of Lyme borreliosis in Canada. Can Commun Dis Rep 2008;34:1-19.

10. Vrbova L, Middleton D. Descriptive epidemiology of Lyme disease in Ontario: 1999-2004. Public Health Agency of Canada. Available at: http://www.phac-aspc.gc.ca/publicat/ ccdr-rmtc/06vol32/dr3221a-eng.php\#ref (accessed Nov 7, 2011).

11. Garcia-Monco JC, Gomez BM, Estrade L. Painful lumbosacral plexitis with increased ESR and Borrelia burgdorferi infection. Neurology 1993;43:1269.

12. Paparone PW. Polymyalgia rheumatica or Lyme disease? How to avoid misdiagnosis in older patients. Postgrad Med 1995;97:161-70. 